\title{
ANALISIS KEPUASAN MASYARAKAT TERHADAP PELAYANAN PUBLIK DI BADAN PELAYANAN PERIZINAN TERPADU DAN PENANAMAN MODAL (BP2TPM) KOTA BANJARMASIN
}

\author{
Umar Makawi, Abdul Haliq \\ Universitas Islam Kalimantan Muhammad Arsyad Al Banjari \\ Email: umarmakawi@gmail.com
}

\begin{abstract}
The purpose of this study was to determine the level of community satisfaction with the public services provided by the Integrated Licensing Public Service Agency and Investment (BP2TPM) of Banjarmasin City, besides that it was also intended to find out the differences in community characteristics, such as age and level of education with satisfaction with service public. This study uses a quantitative approach, with a sample of 60 people, while the data analysis uses Chi Square Goodness Of Fit and Chi Square Test Of Independence. The results showed that the bureaucracy services provided by BP2TPM, most respondents $30 \%$ argued that they were quite satisfied with the licensing services provided by the agency. In addition there are significant differences between gender and community satisfaction, other results show there is no difference between age and community satisfaction, this means that the performance of the service units at BP2TPM does not discriminate or differ in providing services to the community in terms of age level. As well as there is no difference between the level of education and community satisfaction, this means that the service at BP2TPM does not discriminate in providing services to the community.
\end{abstract}

Keywords: service quality, public satisfaction, public service

\section{PENDAHULUAN}

Penerapan Kebijakan Otonomi Daerah di Indonesia menimbulkan harapan besar bagi masyarakat, terutama dalam hal peningkatan pelayanan publik. Tuntutan masyarakat telah berkembang dengan menginginkan adanya birokrasi dalam organisasi pemerintahan yang profesional khususnya dalam pelaksanaan pelayanan publik yang berkualitas.

Pada Otonomi Daerah, urusan manajemen pelayanan menjadi kewenangan pemerintah Daerah sehingga akan mendekatkan jarak antara pemberi pelayanan dan yang dilayani. Pemerintah Daerah dianggap dapat lebih memahami keinginan penduduk lokal sehingga pengambilan keputusan dalam penyediaan pelayanan lebih responsif terhadap permintaan masyarakat (Utomo, 2008:161-167).

Pemberian pelayanan publik oleh aparatur pemerintah kepada masyarakat merupakan implikasi dari fungsi aparat Negara sebagai pelayan masyarakat sehingga kedudukan aparatur pemerintah dalam pelayanan umum (Publik servic) sangat strategis karena akan menentukan sejauhmana pemerintah mampu memberikan pelayanan yang sebaik-baiknya bagi masyarakat dan sejauhmana Negara telah menjalankan perannya dengan baik sesuai dengan tujuannya. Pelayanan publik merupakan kegiatan yang dilakukan oleh seorang atau sekelompok orang atau instansi tertentu dengan tujuan memberikan bantuan pelayanan yang akan mempermudah masyarakat untuk mencapai tujuan tertentu.

Menurut UU No 25 tahun 2009, Bab 1 pasal 1 ayat 1 tentang pelayanan publik, Mendefinisikan bahwa pelayanan publik adalah kegiatan atau rangkaian kegiatan dalam rangka pemenuhan kebutuhan pelayanan sesuai dengan peraturan perundang-undangan bagi setiap warga Negara dan penduduk atas barang, jasa, 
dan pelayanan administratif yang disediakan oleh penyelenggara pelayanan publik.

Fenomena yang sering terjadi dalam birokrasi di Indonesia adalah masih adanya masyarakat yang kecewa terhadap pelayanan publik dan birokrasi pemerintahan, harapan masyarakat untuk mendapatkan pelayanan terbaik dari pemerintah nyaris tinggal harapan. Karena kondisi penyelenggaraan pelayanan publik masih dihadapkan pada sistem pemerintahan yang belum efektif dan efisien. Hal ini dapat dilihat dari banyaknya keluhan dan pengaduan dari masyarakat baik secara langsung maupun tidak langsung, karena prosedur yang berbelit-belit, banyaknya biaya yang harus dikeluarkan, persyaratan yang tidak transparan, sikap petugas yang kurang merespon sehingga menimbulkan citra yang kurang baik.

Kualitas pelayanan memiliki hubungan yang erat dengan kepuasan masyarakat. Kualitas memberikan suatu dorongan kepada masyarakat untuk menjalin hubungan yang baik dengan pemerintah. Dalam jangka yang panjang, ikatan seperti ini memungkinkan pemerintah untuk memahami dengan seksama harapan masyarakat serta kebutuhan mereka. Dengan demikian pemerintah dapat meningkatkan kepuasan masyarakat di mana pemerintah memaksimumkan pengalaman masyarakat yang kurang menyenangkan (Atmawati dan Wahyuddin, 2007:1-12).

Salah satu pelayanan publik adalah Badan Pelayanan Perizinan Terpadu dan Penanaman Modal (BP2TPM), badan ini merupakan salah satu perangkat pemerintah Daerah di Kota Banjarmasin yang menerapkan sistem pelayanan satu pintu. BP2TPM sebagai instansi yang khusus bertugas memberikan pelayanan secara terpadu sehingga memudahkan masyarakat dan dunia usaha dalam memperoleh perizinan, yang dapat mencerminkan suatu bentuk pelayanan yang transparan akan informasi biaya, waktu pengurusan surat izin dan prosedur pelayanan, yang di harapkan mampu memberikan pelayanan publik yang berkualitas sesuai dengan tuntutan dan harapan masyarakat. Berdasarkan latar belakang yang dikemukakan tersebut, maka penulis tertarik untuk menganalis kepuasan masyarakat atas pelayanan publik yang diberikan oleh BP2TPM.

\section{METODE PENELITIAN}

Penelitian ini menggunakan pendekatan kuantitatif, yaitu penelitian yang menjelaskan penyebab fenomena sosial melaui pengukuran obyektif dan analisis numerical (Masyhuri, 2008:14). Pengumpulan data dilakukan dengan kuesioner yang berisi 12 pertanyaan terdiri 3 pertanyaan karakteristik masyarakat dan 9 pertanyaan kepuasan masyarakat terhadap kualitas pelayanan publik seperti persyaratan pelayanan, prosedur pelayanan, waktu pelayanan, biaya pelayanan, produk spesifikasi, kompetensi pelaksana pelayanan, perilaku pelaksana pelayanan, maklumat pelayanan, dan penanganan pengaduan. Sampel penelitian ini berjumlah 60 orang, dengan menggunakan teknik sampling non probability sampling dengan jenis purposif sampling. Analisa data penelitian ini menggunakan Chi Square Goodness Of Fit dan Chi Square Test Of Independence.

\section{HASIL DAN PEMBAHASAN}

Survei kepuasan masyarakat merupakan suatu keharusan yang dilakukan oleh semua pelayanan publik di birokrasi pemerintah, hal ini berdasarkan oleh Permen PAN dan RB No. 16 Tahun 2014. Survei kepuasan tersebut meliputi 1). Persyaratan, 2). Prosedur Pelayanan, 3). Waktu Pelayanan, 4). Biaya/Tarif, 5). Produk Spesifikasi Jenis Pelayanan, 6). Kompetensi Pelaksana, 7). Prilaku Pelaksana, 8). Maklumat Pelayanan, 9). Penanganan Pengaduan, Saran dan Masukan. Berikut ini adalah hasil survei kepuasan masyarakat terhadap pelayanan publik di BP2TPM Kota Banjarmasin. 
Tabel 1. Indikator Kepuasan Masyarakat

\begin{tabular}{clcccc}
\hline \multirow{2}{*}{ No. } & \multirow{2}{*}{ Indikator Kepuasan } & \multicolumn{4}{c}{ Kepuasan Masyarakat (\%) } \\
& & KP & CP & P & SP \\
\hline 1. & Persyaratan Pelayanan & - & 16,5 & 45,0 & 38,3 \\
2. & Prosedur Pelayanan & - & 13,3 & 51,7 & 35,0 \\
3. & Waktu Pelayanan & 5,0 & 23,3 & 35,0 & 36,7 \\
4. & Biaya/Tarif & 1,7 & 21,7 & 40,0 & 36,7 \\
5. & Produk Spesifikasi Jenis Pelayanan & - & 20,0 & 51,7 & 28,3 \\
6. & Kompetensi Pelaksana & - & 15,0 & 50,0 & 35,0 \\
7. & Perilaku Pelaksana & - & 13,3 & 48,3 & 38,3 \\
8. & Maklumat Pelayanan & 1,7 & 18,3 & 43,3 & 36,7 \\
9. & Penanganan Pengaduan & - & 18,3 & 50,0 & 31,7 \\
& & & & & \\
\hline
\end{tabular}

Sumber : Data Primer 2017

Berdasarkan hasil analisis survei kepuasan masyarakat dari 9 indikator tersebut dengan menggunakan pendekatan simultan, kemudian dihitung dengan uji satu variable melalui Chi Square Goodness Of Fit diperoleh hasi berikut ini:

Tabel 2. Kepuasan Masyarakat Terhadap Pelayanan BP2TPM

\begin{tabular}{clcc}
\hline No. & Kepuasan Masyarakat & Frekuensi & \% \\
\hline 1. & Kurang Puas & 10 & 16,6 \\
2. & Cukup Puas & 18 & 30,0 \\
3. & Puas & 16 & 26,6 \\
4. & Sangat Puas & 16 & 26,6 \\
\hline & & & \\
\hline
\end{tabular}

Sumber: Analisis Data Primer 2017

Pada Tabel 2 dapat dilihat Kepuasan Masyarakat terhadap pelayanan publik yang diberikan oleh BP2TPM Kota Banjarmasin, sehubungan dengan itu diketahui sebagian besar responden yaitu 18 orang $(30 \%)$ berpendapat Cukup Puas, 16 orang $(26,6 \%)$ berpendapat Puas, 16 orang $(26,6 \%)$ berpendapat Sangat Puas, dan 10 orang $(16,6 \%)$ berpendapat Kurang Puas. Dengan demikian dapat disimpulkan bahwa kepuasan masyarakat atas pelayanan birokrasi yang diberikan oleh BP2TPM termasuk dalam kategori Cukup Puas.

Pada hasil perhitungan diperoleh nilai Chi Square hitung $X^{2}=2,400$, nilai ini kemudian dibandingkan dengan nilai $\mathrm{X}^{2}$ tabel dengan taraf signifikan 0,05 (5\%) pada df 3 yaitu 7,815 . Karena $\mathrm{X}^{2}$ hitung 2,400 $<\mathrm{X}^{2}$ tabel 7,815, maka hipotesis Ho diterima. Dengan demikian dapat disimpulkan bahwa kepuasan masyarakat terhadap pelayanan publik yang diberikan oleh Badan Pelayanan Perizinan Terpadu dan Penanaman Modal (BP2TPM) Kota Banjarmasin berdistribusi normal atau tersebar disemua kategori kepuasan.

Apabila kepuasan masyarakat tersebut dibandingkan dengan karakteristik masyarakat seperti jenis kelamin, umur, dan tingkat pendidikan, maka diperoleh hasil perhitungan sebagai berikut: 
Tabel 3. Perbedaan Jenis Kelamin Dengan Kepuasan Masyarakat

\begin{tabular}{clcccc}
\multirow{2}{*}{ No. } & \multirow{2}{*}{ Jenis Kelamin } & \multicolumn{4}{c}{ Kepuasan Masyarakat $(\mathbf{F})$} \\
& & KP & CP & P & SP \\
\hline 1. & Laki Laki & 6 & 9 & 16 & 13 \\
2. & Perempuan & 4 & 9 & - & 3
\end{tabular}

Sumber: Analisis Data Primer 2017

Tabel di atas menunjukan bahwa masyarakat yang menjadi responden berjenis kelamin Laki-Laki berpendapat pelayanan publik di BP2TPM Kota Banjarmasin termasuk dalam kategori puas yaitu 16 orang $(36,36 \%)$, sedangkan yang berjenis kelamin Perempuan lebih banyak termasuk kategori Cukup Puas atas pelayanan yang diberikan oleh BP2TPM, hal ini berdasarkan 9 orang $(56,25 \%)$ yang termasuk dalam golongan tersebut.

Hasil perhitungan statistik Chi Square Test Of Independent $\left(\mathrm{X}^{2}\right)$ untuk karakteristik jenis kelamin dengan kepuasan masyarakat diperoleh nilai $\mathrm{X}^{2}$ hitung 12,251 dengan probabilitas 0,007. Hasil perhitungan tersebut kemudian dibandingkan dengan nilai $\mathrm{X}^{2}$ tabel pada df 3 pada taraf signifikan $0,05(5 \%)$ yaitu 7,814. Oleh karena $\mathrm{X}^{2}$ hitung lebih besar dari $\mathrm{X}^{2}$ tabel maka hipotesis Ho ditolak. Dengan demikian dapat disimpulkan bahwa terdapat perbedaan antara jenis kelamin dengan kepuasan masyarakat terhadap pelayanan publik yang diberikan oleh Badan Pelayanan Perizinan Terpadu dan Penanaman Modal (BP2TPM) Kota Banjarmasin. Hal ini berarti bahwa kinerja unit pelayanan di BP2TPM tersebut menunjukan adanya perbedaan tingkat kepuasan antara jenis kelamin Laki-Laki dengan Perempuan.

Tabel 4. Perbedaan Umur Dengan Kepuasan Masyarakat

\begin{tabular}{clcccc}
\multirow{2}{*}{ No. } & Tingkatan Umur & \multicolumn{4}{c}{ Kepuasan Masyarakat (F) } \\
& & KP & CP & P & SP \\
\hline 1. & 22 - 32 Tahun & 1 & 7 & 6 & 6 \\
2. & 33-43 Tahun & 6 & 9 & 2 & 6 \\
3. & 44 - 54 Tahun & 3 & 2 & 5 & 4 \\
4. & 55 -65 Tahun & - & - & 3 & -
\end{tabular}

Sumber: Analisis Data Primer 2017

Tabel di atas menunjukan bahwa masyarakat yang berumur antara 22 - 32 Tahun lebih banyak termasuk kategori Cukup Puas yaitu 7 orang (35\%), umur $33-43$ Tahun juga pada kategori yang sama yaitu Cukup Puas yaitu 9 orang $(39,13 \%)$, umur 44 - 54 Tahun lebih banyak termasuk kategori Puas yaitu 5 orang $35,71 \%$ ), dan umur 55 - 65 Tahun termasuk dalam kategori Puas 3 orang (100\%).

Hasil perhitungan statistik Chi Square Test Of Independent diperoleh nilai $\mathrm{X}^{2}$ hitung 16,661 dengan probabilitas 0,054. Hasil perhitungan tersebut kemudian dibandingkan dengan nilai $\mathrm{X}^{2}$ tabel pada df 9 pada taraf signifikan $0,05(5 \%)$ yaitu 16,919 . Oleh karena $\mathrm{X}^{2}$ hitung lebih kecil dari $\mathrm{X}^{2}$ tabel maka hipotesis Ho diterima. Dengan demikian dapat disimpulkan bahwa tidak terdapat perbedaan antara umur dengan kepuasan masyarakat terhadap pelayanan publik yang diberikan oleh Badan Pelayanan Perizinan Terpadu dan Penanaman Modal (BP2TPM) Kota Banjarmasin. Hal ini berarti bahwa kinerja unit pelayanan di BP2TPM tersebut tidak melakukan diskriminasi atau perbedaan dalam memberikan pelayanan kepada masyarakat dari segi tingkatan usia. 
Tabel 5. Perbedaan Tingkat Pendidikan Dengan Kepuasan Masyarakat

\begin{tabular}{clrrrr}
\hline \multirow{2}{*}{ No. } & \multirow{2}{*}{ Tingkatan Umur } & \multicolumn{3}{c}{ Kepuasan Masyarakat (F) } \\
\hline 1. & SLTP / Sederajat & 1 & - & - & - \\
2. & SLTA / Sederajat & 7 & 11 & 10 & 8 \\
3. & Diploma & - & 2 & 2 & - \\
4. & Strata 1 (S1) & 2 & 5 & 4 & 8 \\
\hline
\end{tabular}

Sumber: Analisis Data Primer 2017

Berdasarkan hasil perhitungan Chi Square (X2) untuk karakteristik tingkat pendidikan dengan kepuasan masyarakat diperoleh nilai $\mathrm{X}^{2}$ hitung 10,976 dengan probabilitas 0,277. Hasil perhitungan tersebut kemudian dibandingkan dengan nilai $\mathrm{X}^{2}$ tabel pada df 9 pada taraf signifikan $0,05(5 \%)$ yaitu 16,919 . Oleh karena $\mathrm{X}^{2}$ hitung lebih kecil dari $\mathrm{X}^{2}$ tabel maka hipotesis Ho diterima. Dengan demikian dapat disimpulkan bahwa tidak terdapat perbedaan antara tingkat pendidikan dengan kepuasan masyarakat terhadap pelayanan publik yang diberikan oleh Badan Pelayanan Perizinan Terpadu dan Penanaman Modal (BP2TPM) Kota Banjarmasin. Hal ini berarti bahwa pelayanan di BP2TPM tersebut tidak membeda-bedakan dalam memberikan pelayanan kepada masyarakat.

Berdasarkan pembahasan tersebut dapat disimpulkan bahwa dalam tingkat kepuasan masyarakat terhadap pelayanan publik yang diberikan oleh B2PTPM hanya 26,6\% yang merasa Puas dan Cukup Puas, masih ada masyarakat yang merasa kurang puas atas pelayanan yang diberikan. Selain itu, bila dibandingkan dengan karakteristik masyarakat ternyata jenis kelamin mengalami perbedaan dalam tingkat kepuasan, sedangkan karaktersitik lainnya baik umur maupun tingkat pendidikan tidak mempunyai perbedaan signifikan terhadap kepuasan masyarakat.

\section{KESIMPULAN}

Pelayanan birokrasi yang diberikan oleh BP2TPM, sebagian besar responden 30\% berpendapat Cukup Puas atas pelayanan perizinan yang diberikan oleh instansi tersebut, sedangkan kategori Puas dan Sangat Puas mempunyai nilai yang sama yaitu $26,6 \%$, dan hanya $16,6 \%$ berpendapat Kurang Puas. Dengan demikian dapat disimpulkan bahwa kepuasan masyarakat terhadap pelayanan perizinan yang diberikan BP2TPM termasuk dalam kategori Cukup Puas. Hasil analisis bivariate diperoleh pernyataan terdapat perbedaan signifikan antara jenis kelamin dengan kepuasan masyarakat terhadap pelayanan publik yang diberikan oleh Badan Pelayanan Perizinan Terpadu dan Penanaman Modal (BP2TPM) Kota Banjarmasin. Tidak terdapat perbedaan antara umur dengan kepuasan masyarakat, hal ini berarti bahwa kinerja unit pelayanan di BP2TPM tersebut tidak melakukan diskriminasi atau perbedaan dalam memberikan pelayanan kepada masyarakat dari segi tingkatan usia. Tidak terdapat perbedaan antara tingkat pendidikan dengan kepuasan masyarakat, hal ini berarti bahwa pelayanan di BP2TPM tersebut tidak membeda-bedakan dalam memberikan pelayanan kepada masyarakat.

\section{REFERENSI}

Atmawati, Rustika dan Wahyuddin. 2007. Analisis Pengaruh Kualitas Pelayanan Terhadap Kepuasan Konsumen Pada Matahari Departemen Store Di Solo Grend Mal. Jurnal Ekonomi dan Bisnis Hal 1-12 Universitas Muhammadiyah Surakarta.

Alamsyah. 2011. Karakteristik Universal Pelayanan Publik: Sebuah Tinjauan Teoritik. Jurnal Borneo Administrator. Vol. 7 No 3 tahun 2011. P:353-372.

Atep Adya Barata. 2003. Dasar-Dasar Pelayanan Prima, Penerbit PT Elex Media Komputindo, Klompok Gramedia Jakarta. 
Hardiayansyah. 2011. Kualitas Pelayanan Publik Konsep, Dimensi, Indikator dan Implementasinya. Cetakan I, Penerbit Gava Media. Yogyakarta.

Ibrahim, Amin. 2008. Teori dan Konsep Pelayanan publik Serta Implementasinya. Bandung: Mandar Maju.

Keputusan Menteri Negara Pemberdayaan Aparatur Negara Nomor 63/KEP/M.PAN/7/2013 Tentang Pedoman Umum Penyelenggaraan Pelayanan publik.

KEPMENPAN Nomor 63 tahun 2004 tentang Pedoman Umum Penyelenggaraan Pelayanan publik

Moenir , H.A.S, 2012, Manajemen Pelayanan Umum Di Indonesia, Jakarta, Bumi Askara.

Masyhuri, M. Zainuddin. 2008. Metodologi Penelitian Pendekatan Praktis dan Aplikatif. Penerbit Rafika Aditama, Bandung.

Malhotra, 2005. Riset Penelitian. Penerbit Gramedia Pustaka Utama, Jakarta.

Peraturan Menteri Pendayagunaan Aparatur Negara Dan Reformasi Birokrasi Nomor 16 tahun 2014 tentang pedoman survei kepuasan masyarakat terhadap penyelenggara pelayanan publik.

Penyusunan Standar Pelayanan publik Lembaga Administrasi Negara Republik Indonesia tahun 2003.

Sugiono. 2010. Metode Penelitian Administrasi. Penerbit Alfabeta, Bandung.

Ratminto dan Atik Septi Winarsih. 2007. Manajemen Pelayanan. Yogyakarta: Pustaka Pelajar.

Tjiptono. 2004. Manajemen Jasa. Penerbit Andy, Yogyakarta

Tjiptono, Fendi. 2010. Prinsip-Prinsip Total Quality Service, edisi kedua, Penerbit Andy, Yogyakarta

Utomo, Saddian. 2008. Penanganan pengaduan Masyarakat mengenai pelayanan publik. Jurnal ilmu administrasi dan organisasi. Volume 15, Nomor 3 Sep-Des 2008. P:161-167.

Undang-Undang Republik Indonesia Nomor 25 tahun 2009 , tentang pelayanan publik.
Wasistiono, Sadu. 2001. Manajemen Pemerintahan Daerah. Bandung Alqa Print. 